\title{
Flight and Nutritional Status of Sylvatic Triatoma sordida and Triatoma guasayana
}

\author{
François Noireau $/{ }^{+}$, Jean-Pierre Dujardin*
}

Institut de Recherche pour le Développement, Brasil and Laboratório Nacional e Internacional de Referência em Taxonomia de Triatomíneos, Departamento de Entomologia, Instituto Oswaldo Cruz-Fiocruz, Av. Brasil 4365, 21045-900 Rio de Janeiro, RJ, Brasil *Institut de Recherche pour le Développement, La Paz, Bolivia

Nutritional status relating to flight activity was investigated in natural populations of Triatoma sordida and $\mathrm{T}$. guasayana during the dry season in the Bolivian Chaco. The peak flight activity of both species was unimodal and covered the period 61-180 min after sunset. The weight of insects was used as the indicator of nutritional status. Interspecies comparisons employing the same sex and type of capture showed a higher weight for T. guasayana. No significant difference according to weight was observed between flying insects and those collected in natural ecotopes (hollow trees and bromeliads). More than $87 \%$ of insects collected from natural ecotopes displayed flight ability under the study conditions, explaining their tendency to invade artificial structures during the dry season.

Key words: Triatoma sordida - Triatoma guasayana - flight activity - nutritional status - Bolivia

Triatoma sordida Stal and T. guasayana Wygodzinsky and Abalos are closely related species of Triatominae (Hemiptera, Reduviidae) which are morphologically very similar, occupy a comparable variety of ecotopes, and their distribution overlaps throughout northern Argentina and parts of the Chaco region in Bolivia and Paraguay (Usinger et al. 1966, Schofield 1994). Although they are originally sylvatic species, they are frequently found in peridomestic habitats and have been reported from houses (Forattini 1980, Wisnivesky-Colli et al. 1993, Gajate et al. 1996, Noireau et al. 1998b). Owing to this trend toward domesticity, they may be considered as candidates domiciliary vector for Chagas disease.

Recent studies have shown a high level of genetic differentiation within $T$. sordida populations that might be compatible with biological species (Panzera et al. 1997, Jurberg et al. 1998, Noireau et al. 1998c). In the Bolivian Chaco, T. guasayana and two biological species pertaining to the $T$. sordida complex (named $T$. sordida groups 1 and 2) occur in sympatry (Noireau et al. 1998b). Al-

\footnotetext{
This study received financial support from the UNDP/ World Bank/WHO Special Program for Research and Training in Tropical Disease (grant 940209) and the ECLAT network.

${ }^{+}$Corresponding author. Fax:+55-21-290.9339. E-mail: noireauf@ioc.fiocruz.br

Received 30 June 2000

Accepted 27 September 2000
}

though $T$. sordida group 2 has not yet received formal recognition as a new species, it is considered in this report as a separate species.

In the sylvatic environment, $T$. sordida and $T$. guasayana are found in a wide variety of ecotopes: bird nests, hollow trees, under bark and among roots of trees, palm tree crowns, clumps of bromeliads and under rocks (Barretto 1971, Forattini et al. 1971a, Carcavallo \& Martinez 1985, Diotaiuti et al. 1993). In the Bolivian Chaco, these species were principally collected in hollow trees and bromeliads (Noireau et al. 2000). In the Chaco region, adults of these species have a high potential for dispersal by nocturnal flight during the hot and dry months (August-November) (Wisnivesky-Colli et al. 1993, Noireau et al. 1998b). Studies applied to various triatomine species have shown that starvation was apparently the main cause of flight initiation (Sjogren \& Ryckman 1966, Ekkens 1981, Lehane \& Schofield, 1982, McEwen \& Lehane 1993). Therefore the nutritional status may allow a prediction of the proportion of wild adults likely to fly (Lehane \& Schofield 1982). With regard to $T$. sordida, the relationship between flight initiation and nutritional status was previously studied: the proportion of insects initiating flight declined with increasing weight-length ratio and this species showed a much higher propensity for flight than did T. infestans (Schofield et al. 1991, McEwen \& Lehane 1993). Nevertheless, no study has examined $T$. guasayana which may have a greater flying capacity than $T$. sordida (Abalos \& Wygodzinsky 1951, Wisnivesky-Colli et al. 1993). The present study was designed (i) to compare the nutritional status of populations of $T$. sordida and 
T. guasayana collected during flight activity and in natural ecotopes and (ii) to predict the proportion of adults that would initiate dispersive flight amongst those collected in wild ecotopes.

\section{MATERIALS AND METHODS}

Study area - The fieldwork was carried out at La Choza (18 34'516' 'S; 6240'108' 'W), an uninhabited site located in the phytogeographic region of the Chaco, southern part of the Department of Santa Cruz, Bolivia. The main environmental characteristics of this semi-arid region are: (i) 300 $\mathrm{m}$ altitude, (ii) mean annual temperature of $26^{\circ} \mathrm{C}$, (iii) an average annual rainfall of about $600 \mathrm{~mm}$, and (iiii) a marked seasonality, with a dry season from March to October and a wet season the rest of the year. The area is covered by dense vegetation of hardwood trees (4-6 m) with emerging trees up to $12 \mathrm{~m}$ high. In the lowest stratum thorn shrubs, bromeliads and cacti predominate.

Collection of triatomines - The collection of flying triatomines was performed by light trapping during the dry season of 1998 (from 20 August to 10 October). The light system, which operated for $6 \mathrm{~h}$ from the official time of sunset, consisted of a vertical white cloth simultaneously illuminated by a 12-V fluorescent black light tube and a $150-\mathrm{V}$ mercury vapour light. Adult triatomines were also collected in September 1998 from bromeliads and hollow trees. The dissected bromeliads were terrestrial (mainly Bromelia serra and B. hieronymi) and epiphytic (Tillandsia spp.). Insects were captured in hollow trees by means of the trapping system described by Noireau et al. (1998a).
Processing of insects - All collected insects were stored at once in liquid nitrogen and transported to the laboratory. They were classified by sex, weighed individually to the nearest $\mathrm{mg}$ and measured from clypeus to abdominal terminalia using a dissection microscope with micrometer eyepiece (6.4 X magnification). The weight/length ratio or $\mathrm{W} / \mathrm{L}(\mathrm{mg} / \mathrm{mm})$, classically used as marker of nutritional status in Triatominae (Lehane \& Schofield 1982), was calculated for each insect. Finally, the triatomines were taxonomically identified according to the key of Lent and Wygodzinsky (1979) and by isoenzyme analysis as described by Noireau et al. (1998c). Only the isocitrate dehydrogenase enzyme system (EC 1.1.1.42., IDH) was assayed because it provides a reliable differentiation between $T$. sordida group $1, T$. sordida group 2 and $T$. guasayana.

\section{RESULTS}

The analyzed sample consisted of: (i) $82 T$. sordida group 2 and $104 T$. guasayana collected by light trapping; (ii) $42 T$. sordida group 2 and 49 $T$. guasayana recovered from natural ecotopes. $T$. sordida specimens belonging to group 1 were discarded due to their low frequency of capture.

Earliest flights for both $T$. sordida $\mathrm{G} 2$ and $T$. guasayana were registered shortly after sunset (less than 15 min after dusk). The peak activity was almost unimodal and covered the period 61-180 min after dark, according to the species and sex (Fig. 1).

The calculation of the correlation coefficient between the weight and the classical W/L ratio $(\mathrm{R}=0.98)$ indicated that it was acceptable to con-

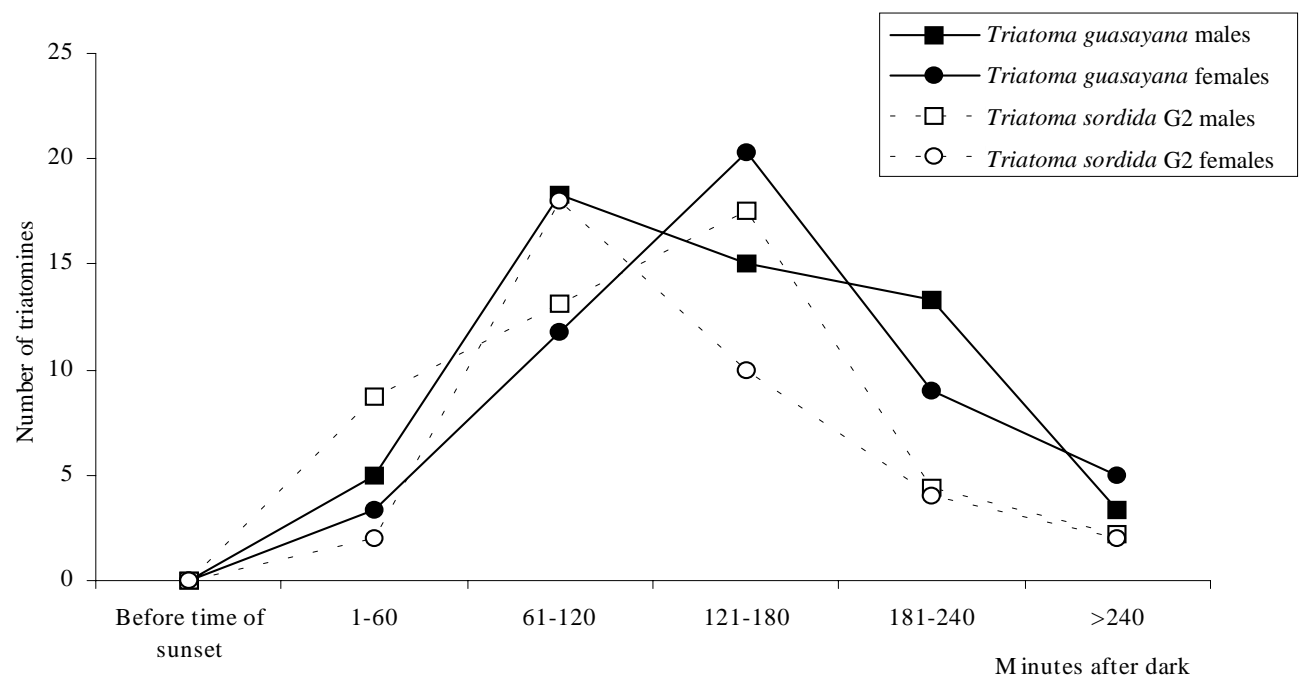

Fig. 1: number of triatomines collected during 60 min periods after sunset. 
sider only weight for further study. Data relating to the frequency distribution of ranked weight classes according to species and sex were achieved for specimens from light collection and natural ecotopes. The pattern of lines was clearly unimodal but did not present a normal distribution (Fig. 2a,b). The mean and standard deviation of modes were calculated according to species, sex and method of collection (Table). The mean weight was consistently higher in females, with significant differences except for $T$. sordida collected by light trapping (Kruskal-Wallis test, $P=0.096$ ). For the same species and sex, no significant difference was detected in the mean value of weight according to the capture method (light trapping vs natural ecotopes). All interspecies comparisons for the same sex and type of capture showed a higher weight for $T$. guasayana $(P<0.0001)$. If we consider, according to species and sex, the higher weight of adults captured by light trapping as an extreme value allowing flight, the majority of insects collected from natural ecotopes would be expected to display flight ability under the study conditions (87\% of $T$. sordida and T. guasayana females, $94.7 \%$ and $96.2 \%$ of males, respectively).

\section{DISCUSSION}

Many authors have reported nocturnal flights of Triatominae, among them the main vectors of Chagas disease T. infestans and Rhodnius prolixus which show peak flight activity just after sunset (Gómez-Núñez 1969, Lehane \& Schofield 1976, 1981). Forattini et al. (1971b) reported that $T$. sordida had a substantial capacity for active dispersal and its flight behaviour was later studied by Schofield et al. (1991) and McEwen and Lehane (1993). Our data show that flight is initiated after sunset with a almost unimodal pattern in both species. The flight activity of $T$. sordida and $T$. guasayana is crepuscular and almost all our collections were made between sunset and the following $5 \mathrm{~h}$, under total darkness but when temperature and saturation deficiency are still relatively high. These observations are in agreement with
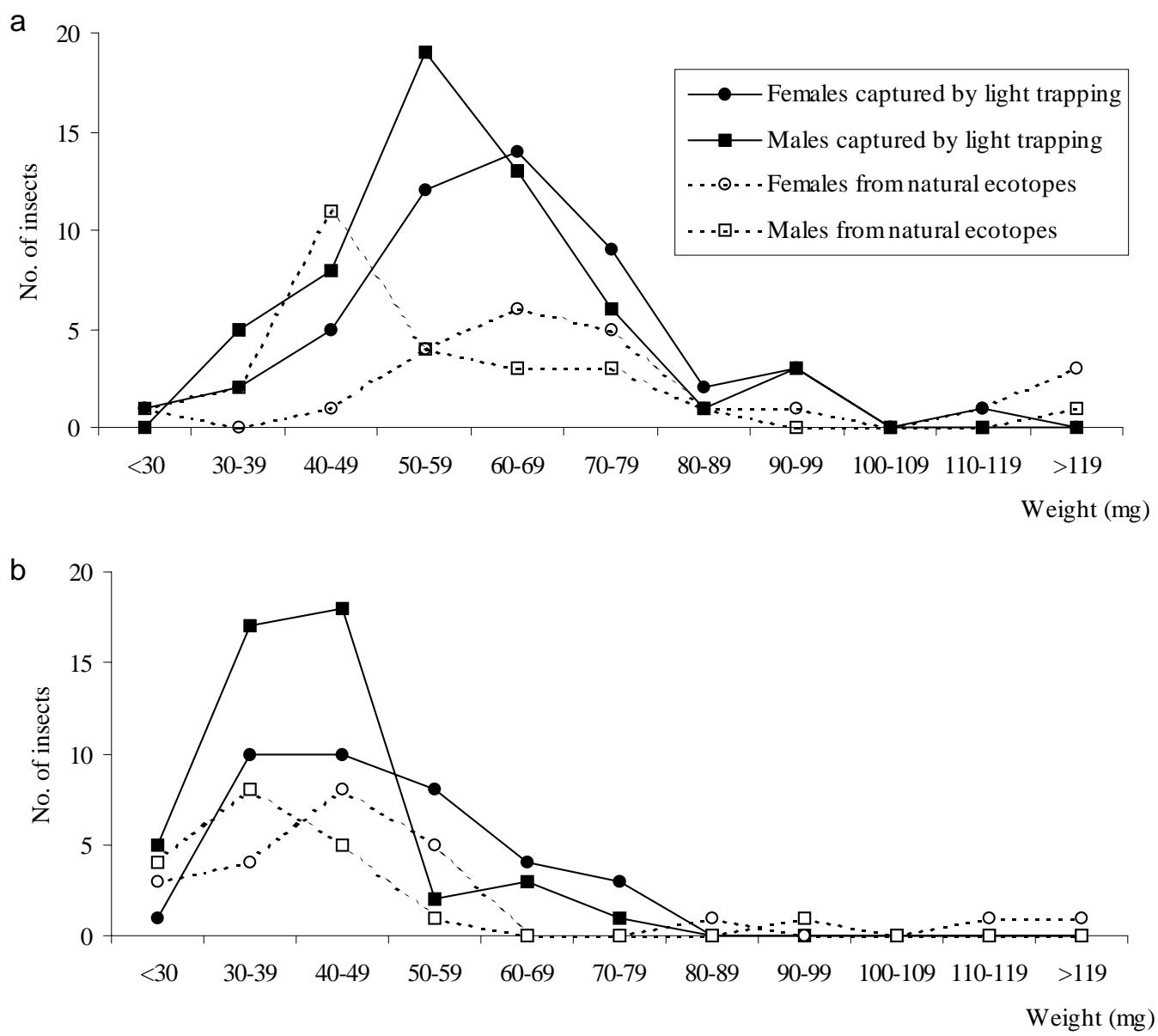

Fig. 2: weight distribution (mg) according to sex and type of collection method. a: Triatoma guasayana; b: T. sordida 
TABLE

Mean weight (mg) of triatomines according to species and type of collecting method

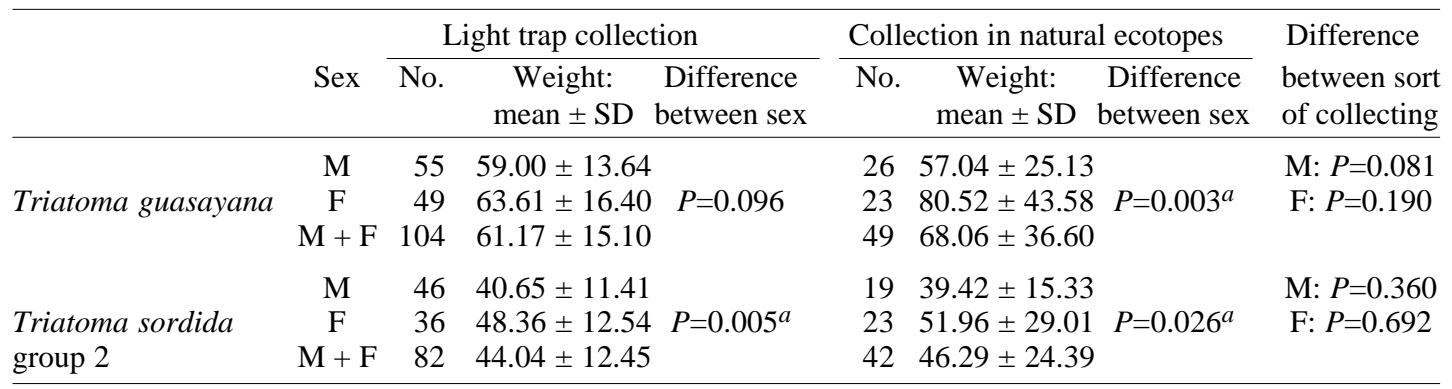

$a$ : significative difference by Kruskal-Wallis test

studies performed on T. rubida, T. recurva and $T$. sordida (Ekkens 1981, Lehane \& Schofield 1982, Schofield et al. 1991). Nevertheless, as T. sordida and $T$. guasayana were generally captured far away from the light source (radius of $5 \mathrm{~m}$ ), it is worth noting that their arrival time was roughly estimated.

In the Argentinean Chaco where both species are endemic, Wisnivesky-Colli et al. (1993) captured more $T$. guasayana than $T$. sordida by light trapping from October to November and slightly more females than males. Our captures, performed early in the season (from August to October), show a predominance of males. For T. recurva, Ekkens (1981) observed that males were more common early in the season whereas later the majority of insects collected were females.

The flying dispersal of starved $T$. sordida and T. guasayana during the dry season may relate to the peak emergence time of adult forms (the biological cycle of $T$. sordida and $T$. guasayana has a duration of approximately one year; Carcavallo \& Martínez 1985) and the seasonal climatic conditions favouring flight activity.

The only comparative field study on the nutritional status between flying/resting triatomines of the same species was performed by Schofield (1980) who examined domestic T. infestans vs flying adults and demonstrated a more favourable nutritional status (higher W/L ratio) among the insects collected inside houses. To compare the nutritional status of $T$. sordida and T. guasayana, we discarded the $\mathrm{W} / \mathrm{L}$ ratio and used only weight. This change of variable allowed an improved statistical analysis of the data since ratios generally have poor statistical properties. Our data illustrate the typical weight profiles of wild populations of $T$. sordida and $T$. guasayana. Unexpectedly, we did not observe significant differences between flying insects and those collected in natural ecotopes. Two hypothesis may be suggested for explanation: (i) dur- ing the dry season, the likely associated hosts (rodents and marsupials) enlarge their home range and a decrease of their populations occurs; consequently, the insects have less access to blood sources and become temporarily undernourished; (ii) in consequence of a limited access to mammalian hosts throughout the year, triatomines exhibit a chronic undernourished status. Only studies carried out during the rest of the year would clarify this issue. Our data concerning the nutritional status of $T$. sordida and $T$. guasayana during the dry season indicate the ability for dispersive flight for almost the whole of adult forms. This would explain their tendency to invade artificial structures during the dry season as observed in the Argentinean and Bolivian Chaco (WisniveskyColli et al. 1993, Noireau et al. 1998b).

\section{ACKNOWLEDGEMENTS}

To Rosmary Flores and Teresa Gutierrez for giving invaluable assistance in the field work.

\section{REFERENCES}

Abalos JW, Wygodzinsky P 1951. Las Triatominae Argentinas (Reduviidae, Hemiptera), Instituto Medico Regional, Tucumán, 179 pp.

Barretto MP 1971. Estudos sôbre reservatórios e vectores silvestres do Trypanosoma cruzi. XLV: inquérito preliminar sôbre triatomíneos silvestres no sul do Estado de Mato Grosso, Brasil (Hemiptera: Reduviidae). Rev Bras Biol 31: 225-233.

Carcavallo RU, Martínez A 1985. Biología, ecología y distribución geográfica de los triatominos americanos. In RU Carcavallo, JE Rabinovich, RJ Tonn (eds), Vol. 1, Factores Biológicos y Ecológicos en la Enfermedad de Chagas, OPS-ECO/MSASSNCH, Buenos Aires, p. 149-208.

Diotaiuti L, Loiola CF, Falcão PL, Dias JCP 1993. The ecology of Triatoma sordida in natural environments in two different regions of the state of Minas Gerais, Brazil. Rev Inst Med Trop São Paulo 35: 237-245.

Ekkens DB 1981. Nocturnal flights of Triatoma (Hemi- 
ptera: Reduviidae) in Sabino Canyon, Arizona. $J$ Med Entomol 18: 211-227.

Forattini OP 1980. Biogeografia, origem e distribuição da domiciliação de triatomíneos no Brasil. Rev Saúde Públ 14: 265-299.

Forattini OP, Ferreira OA, Rocha e Silva EO, Rabello EX, Santos JLF 1971a. Aspectos ecológicos da tripanossomíase americana. II. Distribuição e dispersão local de triatomíneos em ecótopos naturais e artificiais. Rev Saúde Públ 5: 163-191.

Forattini OP, Rocha e Silva EO, Ferreira OA, Rabello EX, Pattoli DGB 1971b. Aspectos ecológicos da tripanossomose americana. III. Dispersão local de triatomíneos, com especial referência ao Triatoma sordida. Rev Saúde Públ 5: 193-205.

Gajate PP, Bottazi V, Pietrokovsky S, Wisnivesky-Colli C 1996. Potential colonization of the peridomicile by Triatoma guasayana (Hemiptera: Reduviidae) in Santiago del Estero, Argentina. J Med Entomol 33: 635-639.

Gómez-Núñez JC 1969. Resting places, dispersal and survival of Co60-tagged adult Rhodnius prolixus. $J$ Med Entomol 6: 83-86.

Jurberg J, Galvão C, Lent H, Monteiro F, Macedo C, Panzera F, Pérez R 1998. Revalidação de Triatoma garciabesi Carcavallo, Cichero, Martinez, Prosen \& Ronderos 1987 (Hemiptera-Reduviidae). Entomol Vect 5: 107-122.

Lehane MJ, Schofield CJ 1976. Preliminary report on flight by some triatomine bugs. Trans $R$ Soc Trop Med Hyg 70: 526.

Lehane MJ, Schofield CJ 1981. Field experiments of dispersive flight by Triatoma infestans. Trans $R$ Soc Trop Med Hyg 75: 399-400.

Lehane MJ, Schofield CJ 1982. Flight initiation in Triatoma infestans (Klug) (Hemiptera: Reduviidae). Bul Entomol Res 72: 497-510.

Lent H, Wygodzinsky P 1979. Revision of the Triatominae (Hemiptera, Reduviidae), and their significance as vectors of Chagas disease. Bul Am Mus Nat Hist 163: 127-520.

McEwen PK, Lehane MJ 1993. Factors influencing flight initiation in the triatomine bug Triatoma sordida (Hemiptera: Reduviidae). Insect Sc Appl 14: 461464.
Noireau F, Flores R, Gutierrez T, Abad-Franch F, Flores E, Vargas F 2000. Natural ecotopes of Triatoma infestans dark morph and other wild triatomines in the Bolivian Chaco. Trans R Soc Trop Med Hyg 94: 23-27.

Noireau F, Flores R, Vargas F 1998a. Trapping of silvatic Triatominae (Reduviidae) in hollow trees. Trans $R$ Soc Trop Med Hyg 93: 13-14.

Noireau F, Gutierrez T, Flores R, Brenière F, Bosseno MF, Wisnivesky-Colli C 1998b. Ecogenetics of Triatoma sordida and T. guasayana (Hemiptera: Reduviidae) in the Bolivian Chaco. Mem Inst Oswaldo Cruz 94: 451-457.

Noireau F, Gutierrez T, Zegarra M, Flores R, Brenière F, Cardozo L, Dujardin JP 1998c. Cryptic speciation in Triatoma sordida (Hemiptera: Reduviidae) from the Bolivian Chaco. Trop Med Int Health 3: 364-372.

Panzera F, Hornos S, Pereira J, Cestau R, Canale D, Diotaiuti L, Dujardin JP, Perez R 1997. Genetic variability and geographic differentiation among three species of triatomine bugs (Hemiptera: Reduviidae). Am J Trop Med Hyg 57: 732-739.

Schofield CJ 1980. Nutritional status of domestic populations of Triatoma infestans. Trans $R$ Soc Trop Med Hyg 74: 770-778.

Schofield CJ 1994. Triatominae: Biology and Control, Eurocommunica Publications, Bognor Regis, UK, $80 \mathrm{pp}$.

Schofield CJ, Lehane MJ, McEwan P, Catalá SS, Gorla DE 1991. Dispersive flight by Triatoma sordida. Trans $R$ Soc Trop Med Hyg 85: 676-678.

Sjogren RD, Ryckman RE 1996. Epizootiology of Trypanosoma cruzi in southwestern North America. Part VIII. Nocturnal flights of Triatoma proctata (Uhler) as indicated by collections in black light traps (Hemiptera, Reduviidae, Triatominae). J Med Entomol 3: 81-92.

Usinger RL, Wygodzinsky P, Ryckman RE 1966. The biosystematics of Triatominae. Annual Rev Entomol 11: 309-330.

Wisnivesky-Colli C, Gürtler RE, Solarz ND, Schweigmann NJ, Pietrokovsky SM, Alberti A, Flo, J 1993. Dispersive flight and house invasion by Triatoma guasayana and Triatoma sordida in Argentina. Mem Inst Oswaldo Cruz 88: 27-32. 
